\title{
Review Article \\ Hydrogen Gas Presents a Promising Therapeutic Strategy for Sepsis
}

\author{
Keliang Xie, ${ }^{1,2}$ Lingling Liu, ${ }^{1,2}$ Yonghao Yu, ${ }^{1,2}$ and Guolin Wang ${ }^{1,2}$ \\ ${ }^{1}$ Department of Anesthesiology, General Hospital of Tianjin Medical University, Tianjin 300052, China \\ ${ }^{2}$ Tianjin Institute of Anesthesiology, Tianjin 300052, China \\ Correspondence should be addressed to Yonghao Yu; tougaozy2011@126.com
}

Received 7 February 2014; Accepted 1 April 2014; Published 16 April 2014

Academic Editor: Baoli Cheng

Copyright (c) 2014 Keliang Xie et al. This is an open access article distributed under the Creative Commons Attribution License, which permits unrestricted use, distribution, and reproduction in any medium, provided the original work is properly cited.

\begin{abstract}
Sepsis is characterized by a severe inflammatory response to infection. It remains a major cause of morbidity and mortality in critically ill patients despite developments in monitoring devices, diagnostic tools, and new therapeutic options. Recently, some studies have found that molecular hydrogen is a new therapeutic gas. Our studies have found that hydrogen gas can improve the survival and organ damage in mice and rats with cecal ligation and puncture, zymosan, and lipopolysaccharide-induced sepsis. The mechanisms are associated with the regulation of oxidative stress, inflammatory response, and apoptosis, which might be through $\mathrm{NF}-\kappa \mathrm{B}$ and $\mathrm{Nrf} 2 / \mathrm{HO}-1$ signaling pathway. In this paper, we summarized the progress of hydrogen treatment in sepsis.
\end{abstract}

\section{Introduction}

Sepsis is defined as the presence (probable or documented) of infection together with systemic manifestations of infection [1]. Severe sepsis is defined as sepsis plus sepsisinduced organ dysfunction or tissue hypoperfusion [1]. Sepsis-induced tissue hypoperfusion is defined as infectioninduced hypotension, elevated lactate, or oliguria [1]. Septic shock is defined as sepsis-induced hypotension persisting despite adequate fluid resuscitation [1]. Sepsis and its various adverse sequelae, such as septic shock, acute respiratory distress syndrome (ARDS), and multiple organ dysfunction syndrome (MODS), continue to be a leading cause of mortality in intensive care unit (ICU) and a major public health burden throughout the world [2]. With recent dramatic advances in powerful antibiotics and monitoring devices, the mortality rate has been decreased over the past half century [3]. However, the number of people dying from sepsis continues to rise annually owing to the increasing morbidity. It is estimated that about 18 million cases of severe sepsis occur annually worldwide and the incidence rate of sepsis is increased by $1.5 \% \sim 8 \%$ annually $[4,5]$. At present, there are more than 1,000,000 cases of severe sepsis among hospitalized patients each year in the USA with a total annual cost of $\$ 16.7$ billion $[6,7]$. In China, the occurrence rate of severe sepsis in surgical ICU is $8.68 \%$ with a hospital mortality rate of $48.7 \%[8,9]$.

The pathogenesis and mechanisms of sepsis are complex and not fully understood, which include the excessive release of inflammatory cytokines, the action of oxidative stress (excessive release of reactive oxygen species, ROS), intestinal bacteria and endotoxin translocation, neutrophil dysfunction, microcirculatory impairment, mitochondrial dysfunction, the imbalance between oxygen supply and oxygen consumption, immune and metabolic disorders, and coagulation disorders [10-15]. Our previous studies have found that the uncontrolled inflammatory response and oxidative stress are crucial to the pathogenesis of sepsis, MODS, and ultimately death [16-18]. In addition, it should be noted that genetic variations partially determine individual susceptibility to sepsis. An increasing number of candidate genes have been implicated in sepsis susceptibility, such as macrophage migration inhibitory factor, plasminogen activator inhibitor 1, protein C, and miRNA [19].

However, even when sepsis is timely recognized, there is no effective therapy to sepsis, except antibiotics, fluids, and vasopressors $[9,20]$. Disappointedly, undeniable successes in numerous animal studies are not consistent with that 
in clinical trials, such as direct anti-inflammatory strategies including anti-TNF- $\alpha$, IL-1-based therapies, high-dose corticosteroids, and administration of activated protein $\mathrm{C}$, which make the researches about pathogenesis and clinical treatment of sepsis troubled [10, 21-23]. The novel interventional strategies of sepsis should be invented to reduce mortality in sepsis.

Molecular hydrogen $\left(\mathrm{H}_{2}\right)$, the smallest, lightest, and most element in the universe, is colorless, odorless, and certain antioxidant. Many years ago, $\mathrm{H}_{2}$ was regarded as physiological inert gas without more attention from scientists because of relatively low solubility and the difficulty to be absorbed. In 1975, Dole et al. found that exposure to a mixture of 2.5 percent oxygen and 97.5 percent hydrogen at a total pressure of 8 atmospheres for periods up to 2 weeks would cause a regression of squamous cell carcinoma via antioxidant effect [24]. In 1997, Shirahata et al. [25] reported that electrolyzed-reduced water, which dissolved large amounts of $\mathrm{H}_{2}$, had the ability to protect DNA from oxidative damage, suggesting that it could reduce the risk of life style-related diseases and cancer. $\mathrm{H}_{2}$ has also been used in medical applications to prevent decompression sickness in deep-sea divers for safety profiles [26]. In 2001, Gharib et al. [27] reported that treatment with $0.7 \mathrm{MPa}$ hydrogen in a hyperbaric chamber for 2 weeks had significantly protective effects towards schistosomiasis-associated chronic liver inflammation, which was associated with antioxidant and anti-inflammatory properties of $\mathrm{H}_{2}$. It is also proved that molecular hydrogen would directly react with the hydroxyl radical, a highly cytotoxic reactive oxygen species (ROS). In 2007, Ohsawa et al. [28] found that $\mathrm{H}_{2}$ could exert a therapeutic antioxidant activity by selectively reducing hydroxyl radical and peroxynitrite (another cytotoxic ROS) in vitro, making researches about molecular hydrogen become hot around the world. In recent years, many researchers have found that molecular hydrogen can attenuate multiple organ damage, such as brain, spinal cord, heart, lung, liver, kidney, pancreas, and intestine [28-34]. Besides, it is widely proved that $\mathrm{H}_{2}$ or $\mathrm{H}_{2}$-rich saline exerts an effective therapeutic role in many diseases including sepsis, ischemia-reperfusion injury, organ transplantation, stroke, MODS, type 2 diabetes, atherosclerosis, neurodegenerative diseases, and oxygen toxicity [28, 30, 31, 35-40]. However, the mechanisms by which molecular hydrogen provides beneficial effects on many disorders remain unclear, which would be associated with reduction of oxidative stress, inflammation, and apoptosis, as well as regulation of several important signaling pathways.

\section{Advances in Hydrogen Treatment of Sepsis}

We have made several studies about $\mathrm{H}_{2}$ treatment in animal models of sepsis. It is well known that cecal ligation and puncture (CLP) causes lethal peritonitis and sepsis due to a polymicrobial infection that is accompanied by multiple organ damage. We firstly investigate the possible therapeutic effects of $\mathrm{H}_{2}$ on sepsis in a murine model of moderate or severe CLP. For severe CLP (100\% lethality), we ligate the distal three-quarters of the cecum and make a single puncture with a 20-gauge needle; for moderate CLP (30-40\% survival), we ligate the distal one-half of the cecum and make a single puncture with a 21-gauge needle. We find that $\mathrm{H}_{2}$ inhalation starting at 1 and $6 \mathrm{~h}$ after CLP operation significantly improved the survival rate of septic mice with moderate or severe CLP in a concentration- and time-dependent manner [30]. Moreover, $\mathrm{H}_{2}$ inhalation at a therapeutic dose $(2 \%$ and $4 \%)$ has no adverse effects on the saturation level of arterial oxygen and hemodynamic parameters. We further find that $\mathrm{H}_{2}$ treatment provides the beneficial effects on sepsis and sepsis-associated organ damage, including lung, liver, kidney, and brain [30]. Zymosan, a substance derived from the cell wall of the yeast $S$. cerevisiae, can lead to systemic inflammation by inducing a wide range of inflammatory mediators. The zymosan-induced generalized inflammation model has been widely used in many experimental studies for MODS. We also find that $\mathrm{H}_{2}$ improves survival rate and organ damage in zymosan-induced generalized inflammation model [16]. $2 \% \mathrm{H}_{2}$ inhalation for 1 hour beginning at 1 and 6 hours after zymosan injection significantly improves the 14-day survival rate of zymosan-challenged mice from $10 \%$ to $70 \%$. $\mathrm{H}_{2}$ treatment significantly mitigates the impairments of liver and kidney function in the zymosan-challenged mice [17]. Intratracheal administration of lipopolysaccharide (LPS), the major component of the outer membrane of Gram-negative bacteria, is a well-established model of acute lung injury. Using this model, we find $2 \% \mathrm{H}_{2}$ or hydrogen-rich saline can exert protective effects in a mouse model of acute lung injury [29]. Meanwhile, combination therapy with $\mathrm{H}_{2}$ (2\%) and hyperoxia (98\%) increases the 14-day survival rate of moderate sepsis mice to $100 \%$ and the 7 -day survival rate of severe sepsis mice from $0 \%$ to $70 \%$ and alleviates injuries of lung, liver, and kidney in moderate and severe sepsis [41]. Similarly, we find that $2 \% \mathrm{H}_{2}$ inhalation significantly ameliorates shortand long-time cognitive function in sepsis survivors (unpublished data). In addition, we find that hydrogen-rich saline can significantly improve the outcome and cardiac function in a rat model of septic shock (unpublished data). Thus, $\mathrm{H}_{2}$ or hydrogen-rich saline may be an effective therapeutic strategy for patients with sepsis (Table 1).

\section{Mechanisms about Hydrogen Treatment of Sepsis}

3.1. Anti-Inflammatory Effects. Sepsis is associated with a systemic inflammatory response, mediated by vascular endothelial cells and innate immune cells, including neutrophils, macrophages, and monocytes [48]. The releases of proinflammatory cytokines and chemokines, including tumor necrosis factor- (TNF-) $\alpha$, interleukin- (IL-) 1, IL-6, high-mobility group box- (HMGB-) 1, and monocyte chemoattractant protein- (MCP-) 1, as the most important cytokines mediating the acute phase of inflammatory response, normally triggers beneficial host innate immune response to confine the infection and tissue damage. However, in sepsis, the excessive and prolonged production of these cytokines can produce overwhelming inflammatory response, which is even more deadly than the original infection. These inflammatory 
TABLE 1: Effects of molecular hydrogen treatment on sepsis.

\begin{tabular}{|c|c|c|c|c|c|}
\hline Drugs & Authors & $\begin{array}{l}\text { Animal or cell } \\
\text { type }\end{array}$ & Animal or cell model & $\begin{array}{l}\text { Administration dose } \\
\text { and way }\end{array}$ & Effect \\
\hline $2 \%$ hydrogen & $\begin{array}{l}\text { Liu et al. } \\
(2013)[42]\end{array}$ & Wister rats & $\begin{array}{l}15 \mathrm{mg} / \mathrm{kg} \text { LPS } \\
\text { (septic shock) }\end{array}$ & $\begin{array}{l}\text { Inhalation for } 2 \mathrm{~h} \\
\text { after LPS injection }\end{array}$ & $\begin{array}{l}\text { Anti-inflammatory (IL-6, IL-8, TNF- } \alpha \text {, } \\
\text { and MPO) } \\
\text { Antioxidant (.OH, MDA, and SOD) } \\
\text { Inhibition of apoptosis (Fas, Bcl-2) }\end{array}$ \\
\hline $\begin{array}{l}\text { Hydrogen-rich } \\
\text { saline }\end{array}$ & $\begin{array}{l}\text { Chen et al. } \\
(2013)[43]\end{array}$ & $\begin{array}{l}\text { RAW } 264.7 \\
\text { macrophages }\end{array}$ & $1 \mathrm{mg} / \mathrm{mL}$ LPS & $\begin{array}{l}\text { Incubation with } \\
\text { hydrogen-rich saline }\end{array}$ & $\begin{array}{l}\text { Anti-inflammatory (TNF- } \alpha \text {, IL-1 } \beta \text {, } \\
\text { HMGB1, and IL-10) } \\
\text { Nrf2/HO-1 signaling pathway }\end{array}$ \\
\hline $\begin{array}{l}\text { Hydrogen-rich } \\
\text { saline }\end{array}$ & $\begin{array}{l}\text { Xie (2013) } \\
\quad[44]\end{array}$ & Wister rats & CLP & $5 \mathrm{~mL} / \mathrm{Kg}$ or $10 \mathrm{~mL} / \mathrm{Kg}$ & $\begin{array}{l}\text { Anti-inflammatory (MPO) } \\
\text { Antioxidant (iNOS) }\end{array}$ \\
\hline $\begin{array}{l}2 \% \mathrm{H}_{2} \text { and } 98 \% \\
\text { hyperoxia }\end{array}$ & $\begin{array}{l}\text { Xie et al. } \\
\text { (2012) [41] }\end{array}$ & C57BL/6 mice & CLP & $\begin{array}{l}2 \% \mathrm{H}_{2} \text { and } 98 \% \\
\text { hyperoxia for } 3 \mathrm{~h} \text { and } \\
6 \mathrm{~h} \text { after CLP }\end{array}$ & $\begin{array}{l}\text { Anti-inflammatory (TNF- } \alpha \text {, HMGB1, } \\
\text { IL-10, and MPO) } \\
\text { Antioxidant (CAT, SOD, and } \\
\text { 8-iso-PGF2 } \alpha \text { ) }\end{array}$ \\
\hline $\begin{array}{l}\text { Hydrogen-rich } \\
\text { saline }\end{array}$ & $\begin{array}{l}\text { Li et al. (2013) } \\
\qquad[45]\end{array}$ & $\begin{array}{l}\text { Sprague-Dawley } \\
\text { rats }\end{array}$ & CLP & $\begin{array}{l}5 \mathrm{~mL} / \mathrm{Kg} \\
\text { hydrogen-rich saline } \\
\text { at } 0,6 \text {, and } 18 \mathrm{~h} \text { after } \\
\mathrm{CLP}\end{array}$ & $\begin{array}{l}\text { Anti-inflammatory (TNF- } \alpha \text {, IL-6, } \\
\text { HMGB1, IL-10, HMGB1, and MPO) } \\
\text { Antioxidant (MDA, SOD) }\end{array}$ \\
\hline $2 \%$ hydrogen & $\begin{array}{c}\text { Xie et al. } \\
(2012)[46] \\
\end{array}$ & C57BL/6 mice & CLP & $\begin{array}{l}2 \% \mathrm{H}_{2} \text { inhalation for } \\
1 \mathrm{~h} \text { and } 6 \mathrm{~h} \text { after CLP }\end{array}$ & Nrf2/HO-1 signaling pathway \\
\hline $\begin{array}{l}2 \% \text { hydrogen or } \\
\text { hydrogen-rich } \\
\text { saline }\end{array}$ & $\begin{array}{l}\text { Xie et al. } \\
\text { (2012) [29] }\end{array}$ & C57BL/6 mice & $\begin{array}{l}25 \text { ug LPS } \\
\text { (acute lung injury) }\end{array}$ & $\begin{array}{l}2 \% \mathrm{H}_{2} \text { inhalation for } \\
1 \mathrm{~h} \text { and } 6 \mathrm{~h} \text { after LPS } \\
\text { given or } 10 \mathrm{~mL} / \mathrm{Kg} \\
\text { hydrogen-rich saline }\end{array}$ & $\begin{array}{l}\text { Anti-inflammatory (TNF- } \alpha \text {, IL- } 1 \beta \text {, IL-6, } \\
\text { IL-10, KC, MIP- } 1 \alpha \text {, MIP-2/MCP-1, and } \\
\text { MPO) } \\
\text { NF- } \kappa \text { B signaling pathway } \\
\text { Inhibition of apoptosis (TUNEL, } \\
\text { caspase-3) }\end{array}$ \\
\hline $2 \%$ hydrogen & $\begin{array}{c}\text { Xie et al. } \\
(2010) \\
{[30,47]}\end{array}$ & C57BL/6 mice & CLP & $\begin{array}{l}2 \% \mathrm{H}_{2} \text { inhalation for } \\
1 \mathrm{~h} \text { and } 6 \mathrm{~h} \text { after CLP }\end{array}$ & $\begin{array}{l}\text { Anti-inflammatory (HMGB1, MPO) } \\
\text { Antioxidant (CAT, SOD, and } \\
8 \text {-iso-PGF2 } \alpha \text { ) }\end{array}$ \\
\hline $2 \%$ hydrogen & $\begin{array}{l}\text { Xie et al. } \\
(2010)[16]\end{array}$ & ICR mice & $\begin{array}{c}1 \mathrm{~g} / \mathrm{Kg} \text { zymosan } \\
\text { (inflammation model) }\end{array}$ & $\begin{array}{l}2 \% \mathrm{H}_{2} \text { inhalation for } \\
1 \mathrm{~h} \text { and } 6 \mathrm{~h} \text { after } \\
\text { zymosan injection }\end{array}$ & $\begin{array}{l}\text { Anti-inflammatory (TNF- } \alpha, \text { HMGB1) } \\
\text { Antioxidant (SOD, 8-iso-PGF } \alpha \text { ) }\end{array}$ \\
\hline
\end{tabular}

cytokines can result in a variety of pathologic phenomena, including priming of the vascular endothelium by synthesis of adhesion molecules, activation of neutrophils, synthesis of cyclooxygenase products, generation of nitrous oxide, ROS, apoptosis, and induction of hypotension and shock-like state [49-52]. It is well known that the excessive production of proinflammatory cytokines causes capillary leakage, tissue injury, and lethal multiple organ failure in severe sepsis [10, $53,54]$. It is also reported that elevated proinflammatory cytokine levels directly correlate with severity and mortality in human sepsis $[55,56]$. The proinflammatory cytokines also lead to activation of the complement and coagulation cascades [57]. Furthermore, proinflammatory cytokines can upregulate the expression of inflammatory mediators via positive feedback loop and, consequently, induce further detrimental phenomena [58].

HMGB1 is a member of the high-mobility group protein superfamily that has been widely studied as nuclear proteins that bind DNA, stabilize nucleosomes, and facilitate gene transcription [59]. HMGB-1 has been implicated in the pathogenesis of inflammatory diseases and proposed to be a crucial mediator in the pathogenesis of many diseases including sepsis, arthritis, cancer, autoimmunity diseases, and diabetes [60]. HMGB1 can interact with various receptors including RAGE, Toll-like receptor- (TLR-) 2, and TLR4 to mediate chemotaxis and release of proinflammatory cytokines in monocytes/macrophages and delayed endotoxin lethality, which is required for the full expression of inflammation in animal models of endotoxemia, sepsis, and arthritis [59, 61]. Furthermore, targeting of HMGB1 with antibodies or specific antagonists has been found to have protective effects in established preclinical inflammatory disease models, including lethal endotoxemia and sepsis [62]. As the late inflammatory cytokine, HMGB1 plays a central role in the inflammatory response, becoming a key therapy to resolve inflammation $[63,64]$.

Our studies show that $\mathrm{H}_{2}$ inhalation can decrease the early proinflammatory cytokines (TNF- $\alpha$, IL- $1 \beta$, and IL-6) and late proinflammatory cytokine (HMGB1) in serum and tissues (lung, liver, and kidney) of preclinical animal models of sepsis [16, 29, 30, 41]. Furthermore, $\mathrm{H}_{2}$ treatment reduces the levels of chemokines (KC, MIP- $1 \alpha$, MIP-2, and MCP-1) in the bronchoalveolar lavage fluid of LPS-induced ALI mice. In addition, $\mathrm{H}_{2}$ treatment decreases LPS-induced neutrophils recruitment into the lungs [29]. All results demonstrate that $\mathrm{H}_{2}$ treatment downregulates the cytokines and chemokines 
in the different mouse models of sepsis. Therefore, it has been suggested to use molecular hydrogen as a new antiinflammatory strategy.

Recently, some studies have shown that neuroinflammation in the central nervous system can cause brain damage in sepsis. The vast release of cytokines, such as TNF- $\alpha$, IL- $1 \beta$, and HMGB1, leads to alterations of cell function, the bloodbrain barrier disruption, and brain dysfunction [65-67]. In particular, HMGB1, released from necrotic neurons via a NR2B-mediated mechanism, promotes cerebral edema via activation of microglial TLR4 and the subsequent expression of the astrocytic water channel, aquaporin-4 in traumatic brain injury [68]. We find that the blood-brain barrier disruption and cognitive dysfunction of sepsis animals are significantly alleviated by $\mathrm{H}_{2}$ treatment, which are associated with the decrease of the levels of proinflammatory cytokines (TNF- $\alpha$, IL-1 $\beta$, and HMGB1) in the cerebral tissue (unpublished data).

With the accumulation of knowledge regarding proinflammatory cytokines produced by the immune system, investigators focus on the physiological mechanisms that maintain homeostasis. So far, various endogenous antiinflammatory mediators are proved to have a capacity to prevent proinflammatory cytokine-mediated diseases [48]. IL-10, as an important anti-inflammatory and immunosuppressant, can mediate the downregulation of inflammatory response by a variety of mechanisms. Importantly, IL-10 can inhibit the generation and release of a variety of cytokines in monocytes/macrophages, such as TNF- $\alpha$, IL-1, IL-8, GMCSF, and G-CSF [69]. IL-10 plays a protective role in the systemic inflammatory response. Combination therapy with $\mathrm{H}_{2}(2 \%)$ and hyperoxia (98\%) significantly increases the IL-10 level in serum and tissues (lung, liver, and kidney) of septic mice with moderate or severe CLP [41].

3.2. Antioxidant Effects. Oxidative stress defines disequilibrium between the levels of produced ROS and the ability of a biological system to detoxify the reactive intermediates [70]. ROS can be generated through several pathways such as direct interactions between redox-active metals and oxygen species via reactions including the Fenton and Haber-Weiss reactions, or by indirect pathways involving the activation of enzymes such as nitric oxide synthase (NOS) or NADPH oxidases. Intracellular accumulation of ROS, such as superoxide anion, hydrogen peroxide, singlet oxygen, hydroxyl radical, and peroxy radical, can arise from toxic insults or normal metabolic processes. These species may perturb the cell's natural antioxidant defense systems, resulting in damage to all of the major classes of biological macromolecules, including nucleic acids, proteins, carbohydrates, and lipids [70]. Furthermore, hydroxyl radical is one of the strongest oxidant species and reacts indiscriminately with nucleic acids, lipids, and proteins [71]. One type of ROS can be converted into another type via antioxidant enzymes in vivo. For example, superoxide dismutase (SOD) converts superoxide anion radical into $\mathrm{H}_{2} \mathrm{O}_{2}$, which is detoxified into $\mathrm{H}_{2} \mathrm{O}$ by either glutathione peroxidase or catalase (CAT) [72]. Besides ROS, reactive nitrogen species (RNS) can mediate nitrosative stress. RNS are generated by the quick reaction of superoxide with nitric oxide (NO), which results in the production of large amount of peroxynitrite $[73,74]$.

In excess, ROS and their by-products that are capable of causing oxidative damage may be detrimental to tissues and organs [75]. Recently, some studies demonstrated that $\mathrm{H}_{2}$ would exert a therapeutic antioxidant activity by selectively reducing hydroxyl radicals (the most cytotoxic ROS) and effectively reverse tissue damage such as transient cerebral ischemia, neonatal cerebral hypoxia-ischemia, liver injury, lung injury, and myocardial injury induced by ischemia and reperfusion [31,32, 76-78]. A growing number of studies have found that excessive production of ROS and RNS plays important roles in the pathogenesis of sepsis [79-81]. Therefore, scavenging ROS, RNS, and their by-products is a critical antioxidant process, which may be a good and critical measure for treating sepsis. We report that $\mathrm{H}_{2}$ treatment significantly decreases the levels of 8-iso-prostaglandin-F2 $\alpha$ (8-iso-PGF $\alpha$ ) in serum, lung, liver, and kidney tissue, which could exactly reflect the level of oxidative stress $[16,29,30]$. The levels of 8 -iso-PGF $2 \alpha$ in serum and tissues are also reduced by combination therapy with $\mathrm{H}_{2}$ and $\mathrm{O}_{2}$ [41]. In addition, our researches find that $\mathrm{H}_{2}$ treatment can significantly improve the activities of antioxidant enzymes (SOD and CAT) in serum and organ tissues of mice of moderate and severe sepsis models $[16,30,41]$. These outcomes suggest that $\mathrm{H}_{2}$ treatment provides beneficial effects on sepsis and sepsis-associated organ damage, which are associated with downregulation of oxidative stress.

3.3. Antiapoptosis Effects. Apoptosis, the regulated destruction of a cell, is a complicated process [82]. Many pathways can lead to activation of cell death. Death proteases are homologous to each other and are part of a large protein family known as the caspases, and blocking caspases can rescue condemned cells from their apoptotic fate. Besides the caspases, mitochondria sequester is a potent cocktail of proapoptotic proteins. Most prominent among these is cytochrome $\mathrm{C}$, the humble electron carrier. Cytochrome C is one of the components required for activation of caspase9 in the cytosol. Bcl-2 family is intimately involved in the regulation of cytochrome $\mathrm{C}$ crossing the mitochondria.

In addition, a role for oxidative stress in apoptosis has been shaped by several independent observations. For many years, direct treatment of cells with oxidants like hydrogen peroxide or redox-active quinones was thought to exclusively cause necrosis, but more recent studies have shown that lower doses of these agents can trigger apoptosis [83].

Apoptosis is a common pathological basis of many diseases, which plays an important role in the development of various diseases. Xiang et al. [84] detect that $2 \% \mathrm{H}_{2}$ inhalation markedly attenuates morphological liver injury and apoptosis by reducing lipid peroxidation such as MDA. Cai et al. [77] find that $2 \% \mathrm{H}_{2}$ therapy in a durationdependent manner significantly reduces the number of positive TUNEL cells and suppresses caspase- 3 and caspase12 activities in neonatal hypoxia-ischemia rat model. We find that $\mathrm{H}_{2}$ inhalation markedly inhibits pulmonary cell 
apoptosis by TUNEL staining in LPS-challenged mice. Similarly, the caspase- 3 activity is significantly increased in the lungs of LPS-challenged animals, which is prevented by $\mathrm{H}_{2}$ treatment [29]. Moreover, $1.3 \% \mathrm{H}_{2}$ can reduce the number of apoptotic positive cells and infarct sizes due to opening of mitochondrial $K_{\text {ATP }}$ channels followed by inhibition of MPTP in the acute myocardial infarction and reperfusion model [85]. Besides, $\mathrm{H}_{2}$-rich saline may effectively decrease the degree of necrosis, apoptosis, and cell autophagy in rats with acute $\mathrm{CO}$ poisoning, which could be related to decrease in the content of Fe and increase in the content of serum $\mathrm{Cu}$ associated with free radical metabolism [86].

3.4. Signaling Pathways. NF- $\kappa \mathrm{B}$ transcription factors also regulate the expression of hundreds of genes that are involved in regulating cell growth, differentiation, development, inflammation, and apoptosis [87]. In quiescent cells, $\mathrm{NF}-\kappa \mathrm{B}$ activity is principally regulated by the $\mathrm{I} \kappa \mathrm{B}$ proteins, which possess ankyrin repeats and are generally inhibitory to DNA binding. The activity of the typical $\mathrm{I} \kappa \mathrm{Bs}$ is controlled through phosphorylation by upstream $\mathrm{I} \kappa \mathrm{B}$ kinases (IKKs). The canonical NF- $\kappa \mathrm{B}$ pathway is activated mostly by the stimulation of proinflammatory receptors, such as the TNF receptor superfamily, the Toll-like receptor family (TLRs), and cytokine receptors for the interleukins [88]. It is also activated by genotoxic agents as well. Phosphorylation of $\mathrm{I} \kappa \mathrm{B} \alpha$ on serines 32 and 36 by the IKK complex (primarily IKK $\beta$ ) targets it for ubiquitination. Subsequently the ubiquitinated $\mathrm{I} \kappa \mathrm{B} \alpha$ is degraded by the proteosome and this unmasks the DNA-binding activity of the p50/RelA heterodimer and also allows it to translocate to the nucleus where it can bind to $\kappa \mathrm{B}$ sites and activate gene transcription. It is well known that NF- $\kappa \mathrm{B}$ regulates gene expression of cytokines, chemokines, and adhesion molecules. Therefore, NF- $\kappa \mathrm{B}$ is increasingly recognized as a crucial player in many steps of regulation of inflammatory responses. Noncanonical NF$\kappa \mathrm{B}$ activation is stimulated by specific TNF receptor family members that signal through the recruitment of TRAF2 and TRAF3 [88]. In addition, different target genes are differentially induced by distinct NF- $\kappa \mathrm{B}$ dimers. Furthermore, NF- $\kappa \mathrm{B}$ subunits also contain sites for phosphorylations and other posttranslational modifications which are important for activation and crosstalk with other signaling pathways [87]. Heme oxygenase-1 (HO-1) and apoptosis-associated factors, including TRAF-1 and Bcl-XL, are also mediated by $N F-\kappa B$ [89]. A previous study indicates that $\mathrm{H}_{2}$ inhalation reduces epithelial apoptosis in ventilator-induced lung injury via NF- $\kappa$ B activation [90]. $\mathrm{H}_{2}$ inhibits TNF- $\alpha$-induced lectin-like oxidized LDL receptor-1 expression by inhibiting the phosphorylation of $\mathrm{I} \kappa \mathrm{B}-\alpha$ and activation of $\mathrm{NF}-\kappa \mathrm{B}$ in endothelial cells [91]. Moreover, $\mathrm{H}_{2}$ can indirectly activate the $\mathrm{NF}-\kappa \mathrm{B}$ signaling through reducing oxygen free radical [28]. However, in our study, $\mathrm{H}_{2}$ treatment inhibits the lung NF- $\kappa \mathrm{B}$ p65 nuclear translocation and DNA-binding activity in LPSchallenged mice [29].

Nuclear factor erythroid 2-related factor 2 (Nrf2) is an important cytoprotective transcription factor [92]. Nrf2 controls the coordinated expression of important antioxidant and detoxification genes (Phase II genes) through a promotor sequence termed the antioxidant response element (ARE). Phase II genes, including heme oxygenase-1 (HO1), glutathione S-transferases (GSTs), and NAD(P)H quinine oxidoreductase, work in synergy to constitute a pleiotropic cellular defense that scavenges reactive oxygen/nitrogen species (ROS/RNS), detoxifies electrophiles and xenobiotics, and maintains intracellular reducing potential. HO-1 is an ubiquitous and redox-sensitive inducible stress protein that degrades heme to CO, iron, and biliverdin [93]. Some studies have found that $\mathrm{Nrf} 2$ is a novel regulator of the innate immune response that dramatically improves survival during experimental sepsis by protecting against dysregulated inflammation [94]. Heme oxygenase-1 (HO-1) and the product of its enzymatic reaction, $\mathrm{CO}$, not only have beneficial anti-inflammatory properties, but also enhance bacterial clearance by increasing phagocytosis and the endogenous antimicrobial response [95]. Some researchers found that hydrogen treatment during exposure to hyperoxia significantly improved blood oxygenation, reduced inflammatory events, and induced HO-1 expression, which did not mitigate hyperoxic lung injury or induce $\mathrm{HO}-1$ in Nrf2-deficient mice [96]. Previous studies investigate that hydrogen gas inhalation significantly promotes the expression of $\mathrm{Nrf} 2$ in septic organs including lung, liver, and kidney. However, hydrogen gas did not improve the survival rate in Nrf2-deficient mice $[46,97]$. Moreover, $\mathrm{H}_{2}$ treatment dose-dependently attenuates the increased levels of proinflammatory cytokines and further increases the level of anti-inflammatory cytokine IL10 with the increase of HO-1 protein expression and activity in LPS-stimulated RAW 264.7 macrophages [43]. Therefore, downstream molecules of Nrf2 signaling pathway play an important role in the pathophysiological process of sepsis.

\section{Hydrogen-Rich Saline Exerts the Same Therapeutic Effect with $\mathbf{H}_{2}$}

Hydrogen-rich saline, in which the concentration of hydrogen is more than $0.6 \mathrm{mmol} / \mathrm{L}$, is easily and safely manufactured [29]. Hydrogen-rich saline can alleviate inflammatory response, inhibit cell apoptosis, and reverse oxidative stress to reduce organ injuries, which would be a good method for clinical application. Currently, it is generally accepted that hydrogen-rich saline exerts an effective therapeutic role in many disorders including sepsis, ischemia-reperfusion injury, allergy, and degenerative diseases [29, 98-100].

In our study, we find that hydrogen-rich saline has similar beneficial effects on LPS-induced lung injury as hydrogen inhalation, which are also associated with inhibition of infiltration of inflammatory cell and activation of NF- $\kappa \mathrm{B}$ [29]. In addition, hydrogen-rich saline effectively ameliorates hemodynamics, vascular reactivity in a dose-dependent manner in rat model of peritonitis-induced septic shock. Meanwhile, vital organ dysfunction, such as heart, lung, liver, and kidney, is significantly mitigated via resolving inflammatory responses and decreasing the iNOS expression [44]. Similarly, hydrogen-rich saline has potential protective effects against 
sepsis by decreasing proinflammatory responses, oxidative stress, and apoptosis in a rat model of polymicrobial sepsis [45]. In addition, hydrogen-rich saline markedly reverses cognitive impairment and mortality in a dose-dependent manner in rats submitted to sepsis by cecal ligation and puncture, which are relative to the suppression of oxidative stress and cell apoptosis [101].

\section{Advantages of $\mathrm{H}_{2}$ or Hydrogen-Rich Saline Treatment of Sepsis}

It is obvious that hydrogen is electronically neutral and has favorable distribution characteristics: it can penetrate biomembranes and diffuse into the cytosol, mitochondria, and nucleus [102]. Despite the moderate reduction activity of $\mathrm{H}_{2}$, its rapid gaseous diffusion might make it highly effective for reducing cytotoxic radicals. Besides, it stands to reason that $\mathrm{H}_{2}$ will react with only the strongest oxidants. $\mathrm{H}_{2}$ is mild enough not to disturb metabolic oxidation reduction reactions or to disrupt ROS involved in cell signaling - unlike some antioxidant supplements with strong reductive reactivity, which increase mortality, possibly by affecting essential defensive mechanisms. Thus, $\mathrm{H}_{2}$ treatment is advantageous for medical procedures without serious unwanted side effects [28]. Furthermore, $\mathrm{H}_{2}$ is neither inflammable nor explosive at low concentrations ( $<4.6 \%$ in air and $4.1 \%$ in pure oxygen) [28]. Moreover, only $2 \%$ hydrogen gas can have obvious protective effects on sepsis. Meanwhile, hydrogen-rich saline is also available and safe for medical applications.

\section{Conclusion}

Although recent treatment modalities and interventions have contributed to the improvement for sepsis patients, the high mortality rate of severe sepsis suggests the necessity for additional therapies. Recently, vigorous experimental studies have been undergone to identify effective therapy of molecular hydrogen for sepsis. What is more, this novel therapy may be tested in clinical situation in the future. However, we should deeply proceed to more experimental researches to investigate the plausible and comprehensive mechanisms of hydrogen to treat sepsis.

\section{Conflict of Interests}

The authors have declared that no conflict of interests exists.

\section{Authors' Contribution}

Keliang Xie and Lingling Liu contributed equally to this work.

\section{Acknowledgments}

This work was supported by the National Natural Science Foundation of China (Nos. 81071533 to Yonghao Yu and 81101409 to Keliang Xie), the Natural Science Foundation of the Tianjin Science Committee (Nos. 11JCYBJC12900 to Yonghao Yu and 13JCQNJC11400 to Keliang Xie), and the
Foundation of Tianjin Bureau of Public Health (2011KZ108 to Keliang Xie).

\section{References}

[1] J. Briegel and P. Mohnle, "International guidelines of the Surviving Sepsis Campaign: update 2012," Der Anaesthesist, vol. 62, no. 4, pp. 304-309, 2013.

[2] F. B. Mayr, S. Yende, and D. C. Angus, "Epidemiology of severe sepsis," Virulence, vol. 5, no. 1, pp. 4-11, 2014.

[3] Y. Okazaki and A. Matsukawa, "Pathophysiology of sepsis and recent patents on the diagnosis, treatment and prophylaxis for sepsis," Recent Patents on Inflammation and Allergy Drug Discovery, vol. 3, no. 1, pp. 26-32, 2009.

[4] G. S. Martin, "Sepsis, severe sepsis and septic shock: changes in incidence, pathogens and outcomes," Expert Review of AntiInfective Therapy, vol. 10, no. 6, pp. 701-706, 2012.

[5] A. Perner, N. Haase, A. B. Guttormsen et al., "Hydroxyethyl starch 130/0.42 versus Ringer's acetate in severe sepsis," The New England Journal of Medicine, vol. 367, no. 2, pp. 124-134, 2012.

[6] G. S. Martin, D. M. Mannino, S. Eaton, and M. Moss, "The epidemiology of sepsis in the United States from 1979 through 2000," The New England Journal of Medicine, vol. 348, no. 16, pp. 1546-1554, 2003.

[7] J. A. Russell, "Management of sepsis," The New England Journal of Medicine, vol. 355, no. 16, pp. 1699-1713, 2006.

[8] B. Cheng, G. Xie, S. Yao et al., "Epidemiology of severe sepsis in critically ill surgical patients in ten university hospitals in China," Critical Care Medicine, vol. 35, no. 11, pp. 2538-2546, 2007.

[9] H. B. Nguyen and D. Smith, "Sepsis in the 21st century: recent definitions and therapeutic advances," American Journal of Emergency Medicine, vol. 25, no. 5, pp. 564-571, 2007.

[10] R. S. Hotchkiss and I. E. Karl, "The pathophysiology and treatment of sepsis," The New England Journal of Medicine, vol. 348, no. 2, pp. 138-150, 2003.

[11] P. Q. Eichacker, C. Natanson, and R. L. Danner, "Surviving sepsis-practice guidelines, marketing campaigns, and Eli Lilly," The New England Journal of Medicine, vol. 355, no. 16, pp. 1640-1642, 2006.

[12] Y. Oba and K. Iwata, "Treatment of neonatal sepsis with immune globulin," The New England Journal of Medicine, vol. 366, no. 1, p. 91, 2012.

[13] W. L. Lee and A. S. Slutsky, "Sepsis and endothelial permeability," The New England Journal of Medicine, vol. 363, no. 7, pp. 689-691, 2010.

[14] E. Abraham, P.-F. Laterre, R. Garg et al., "Drotrecogin alfa (activated) for adults with severe sepsis and a low risk of death," The New England Journal of Medicine, vol. 353, no. 13, pp. 13321341, 2005.

[15] R. S. Hotchkiss, G. Monneret, and D. Payen, "Immunosuppression in sepsis: a novel understanding of the disorder and a new therapeutic approach," The Lancet Infectious Diseases, vol. 13, no. 3, pp. 260-268, 2013.

[16] K. Xie, Y. Yu, Z. Zhang et al., "Hydrogen gas improves survival rate and organ damage in zymosan-induced generalized inflammation model," Shock, vol. 34, no. 5, pp. 495-501, 2010.

[17] J. Mu, K. Xie, L. Hou et al., "Subanesthetic dose of isoflurane protects against zymosan-induced generalized inflammation and its associated acute lung injury in mice," Shock, vol. 34, no. 2, pp. 183-189, 2010. 
[18] L. Hou, K. Xie, N. Li et al., "100\% oxygen inhalation protects against zymosan-induced sterile sepsis in mice: the roles of inflammatory cytokines and antioxidant enzymes," Shock, vol. 32, no. 4, pp. 451-460, 2009.

[19] L. P. Chung and G. W. Waterer, "Genetic predisposition to respiratory infection and sepsis," Critical Reviews in Clinical Laboratory Sciences, vol. 48, no. 5-6, pp. 250-268, 2011.

[20] S. N. Stehr and K. Reinhart, "Sepsis as a global health problemwhy we need a global sepsis alliance," Shock, vol. 39, supplement 1, pp. 3-4, 2013.

[21] R. P. Dellinger, M. M. Levy, A. Rhodes et al., "Surviving Sepsis Campaign: international guidelines for management of severe sepsis and septic shock, 2012," Intensive Care Medicine, vol. 39, no. 2, pp. 165-228, 2013.

[22] P. Brocklehurst, B. Farrell, A. King et al., "Treatment of neonatal sepsis with intravenous immune globulin," The New England Journal of Medicine, vol. 365, no. 13, pp. 1201-1211, 2011.

[23] A. Mackenzie, "Activated protein C for sepsis," The New England Journal of Medicine, vol. 362, no. 12, pp. 1150-1151, 2010.

[24] M. Dole, F. R. Wilson, and W. P. Fife, "Hyperbaric hydrogen therapy: a possible treatment for cancer," Science, vol. 190, no. 4210, pp. 152-154, 1975.

[25] S. Shirahata, S. Kabayama, M. Nakano et al., "Electrolyzedreduced water scavenges active oxygen species and protects DNA from oxidative damage," Biochemical and Biophysical Research Communications, vol. 234, no. 1, pp. 269-274, 1997.

[26] P. Fontanari, M. Badier, C. Guillot et al., "Changes in maximal performance of inspiratory and skeletal muscles during and after the 7.1-MPa hydra 10 record human dive," European Journal of Applied Physiology, vol. 81, no. 4, pp. 325-328, 2000.

[27] B. Gharib, S. Hanna, O. M. S. Abdallahi, H. Lepidi, B. Gardette, and M. de Reggi, "Anti-inflammatory properties of molecular hydrogen: investigation on parasite-induced liver inflammation," Comptes Rendus de l'Academie des Sciences III, vol. 324, no. 8, pp. 719-724, 2001.

[28] I. Ohsawa, M. Ishikawa, K. Takahashi et al., "Hydrogen acts as a therapeutic antioxidant by selectively reducing cytotoxic oxygen radicals," Nature Medicine, vol. 13, no. 6, pp. 688-694, 2007.

[29] K. Xie, Y. Yu, Y. Huang et al., "Molecular hydrogen ameliorates lipopolysaccharide-induced acute lung injury in mice through reducing inflammation and apoptosis," Shock, vol. 37, no. 5, pp. 548-555, 2012.

[30] K. Xie, Y. Yu, Y. Pei et al., "Protective effects of hydrogen gas on murine polymicrobial sepsis via reducing oxidative stress and HMGB1 release," Shock, vol. 34, no. 1, pp. 90-97, 2010.

[31] K. Hayashida, M. Sano, I. Ohsawa et al., "Inhalation of hydrogen gas reduces infarct size in the rat model of myocardial ischemiareperfusion injury," Biochemical and Biophysical Research Communications, vol. 373, no. 1, pp. 30-35, 2008.

[32] K.-I. Fukuda, S. Asoh, M. Ishikawa, Y. Yamamoto, I. Ohsawa, and S. Ohta, "Inhalation of hydrogen gas suppresses hepatic injury caused by ischemia/reperfusion through reducing oxidative stress," Biochemical and Biophysical Research Communications, vol. 361, no. 3, pp. 670-674, 2007.

[33] L. Xiang, J. W. Tan, L. J. Huang et al., "Inhalation of hydrogen gas reduces liver injury during major hepatotectomy in swine," World Journal of Gastroenterology, vol. 18, no. 37, pp. 5197-5204, 2012.

[34] T. Hayashi, T. Yoshioka, K. Hasegawa et al., "Inhalation of hydrogen gas attenuates left ventricular remodeling induced by intermittent hypoxia in mice," American Journal of Physiology: Heart and Circulatory Physiology, vol. 301, no. 3, pp. H1062H1069, 2011.

[35] J. Zheng, K. Liu, Z. Kang et al., "Saturated hydrogen saline protects the lung against oxygen toxicity," Undersea and Hyperbaric Medicine, vol. 37, no. 3, pp. 185-192, 2010.

[36] B. M. Buchholz, D. J. Kaczorowski, R. Sugimoto et al., "Hydrogen inhalation ameliorates oxidative stress in transplantation induced intestinal graft injury," American Journal of Transplantation, vol. 8, no. 10, pp. 2015-2024, 2008.

[37] S. Kajiyama, G. Hasegawa, M. Asano et al., "Supplementation of hydrogen-rich water improves lipid and glucose metabolism in patients with type 2 diabetes or impaired glucose tolerance," Nutrition Research, vol. 28, no. 3, pp. 137-143, 2008.

[38] Y. Fu, M. Ito, Y. Fujita et al., "Molecular hydrogen is protective against 6-hydroxydopamine-induced nigrostriatal degeneration in a rat model of Parkinson's disease," Neuroscience Letters, vol. 453, no. 2, pp. 81-85, 2009.

[39] J. Cai, Z. Kang, K. Liu et al., "Neuroprotective effects of hydrogen saline in neonatal hypoxia-ischemia rat model," Brain Research, vol. 1256, pp. 129-137, 2009.

[40] X. Ji, W. Liu, K. Xie et al., "Beneficial effects of hydrogen gas in a rat model of traumatic brain injury via reducing oxidative stress," Brain Research, vol. 1354, pp. 196-205, 2010.

[41] K. Xie, W. Fu, W. Xing et al., "Combination therapy with molecular hydrogen and hyperoxia in a murine model of polymicrobial sepsis," Shock, vol. 38, no. 6, pp. 656-663, 2012.

[42] W. Liu, L. P. Shan, X. S. Dong et al., "Combined early fluid resuscitation and hydrogen inhalation attenuates lung and intestine injury," World Journal of Gastroenterology, vol. 19, no. 4, pp. 492-502, 2013.

[43] H. G. Chen, K. L. Xie, H. Z. Han et al., "Heme oxygenase-1 mediates the anti-inflammatory effect of molecular hydrogen in LPS-stimulated RAW 264.7 macrophages," International Journal of Surgery, vol. 11, no. 10, pp. 1060-1066, 2013.

[44] K. Xie, "Therapeutic effects of hydrogen-rich saline on peritonitis-induced septic shock in rats," pp. 148-149, 2013.

[45] G. M. Li, M. H. Ji, X. J. Sun et al., "Effects of hydrogen-rich saline treatment on polymicrobial sepsis," Journal of Surgical Research, vol. 181, no. 2, pp. 279-286, 2013.

[46] K. Xie, Y. Yu, L. Hou et al., "Nrf2 is critical in the protective role of hydrogen gas against murine polymicrobial sepsis," British Journal of Anaesthesia, vol. 108, no. 3, pp. 538-539, 2012.

[47] K.-L. Xie, L.-C. Hou, G.-L. Wang, and L.-Z. Xiong, "Effects of hydrogen gas inhalation on serum high mobility group box 1 levels in severe septic mice," Zhejiang da Xue Xue Bao. Yi Xиe Ban, vol. 39, no. 5, pp. 454-457, 2010.

[48] A. Matsuda, A. Jacob, R. Wu et al., "Novel therapeutic targets for sepsis: regulation of exaggerated inflammatory responses," Journal of Nippon Medical School, vol. 79, no. 1, pp. 4-18, 2012.

[49] D. Beasley, J. H. Schwartz, and B. M. Brenner, "Interleukin 1 induces prolonged L-arginine-dependent cyclic guanosine monophosphate and nitrite production in rat vascular smooth muscle cells," The Journal of Clinical Investigation, vol. 87, no. 2, pp. 602-608, 1991.

[50] P. B. Chapman, T. J. Lester, E. S. Casper et al., "Clinical pharmacology of recombinant human tumor necrosis factor in patients with advanced cancer," Journal of Clinical Oncology, vol. 5, no. 12, pp. 1942-1951, 1987.

[51] C. A. Dinarello, "Proinflammatory and anti-inflammatory cytokines as mediators in the pathogenesis of septic shock," Chest, vol. 112, supplement 6, pp. 321S-329S, 1997. 
[52] S. Okusawa, J. A. Gelfand, T. Ikejima, R. J. Connolly, and C. A. DInarello, "Interleukin 1 induces a shock-like state in rabbits. Synergism with tumor necrosis factor and the effect of cyclooxygenase inhibition," The Journal of Clinical Investigation, vol. 81, no. 4, pp. 1162-1172, 1988.

[53] B. Cai, E. A. Deitch, and L. Ulloa, "Novel insights for systemic inflammation in sepsis and hemorrhage," Mediators of Inflammation, vol. 2010, Article ID 642462, 10 pages, 2010.

[54] N. C. Riedemann and P. A. Ward, "Anti-inflammatory strategies for the treatment of sepsis," Expert Opinion on Biological Therapy, vol. 3, no. 2, pp. 339-350, 2003.

[55] J.-P. Mira, A. Cariou, F. Grall et al., "Association of TNF2, a TNF$\alpha$ promoter polymorphism, with septic shock susceptibility and mortality: a multicenter study," The Journal of the American Medical Association, vol. 282, no. 6, pp. 561-568, 1999.

[56] T. van der Poll and S. F. Lowry, "Tumor necrosis factor in sepsis: mediator of multiple organ failure or essential part of host defense?" Shock, vol. 3, no. 1, pp. 1-12, 1995.

[57] H. Moshage, "Cytokines and the hepatic acute phase response," The Journal of Pathology, vol. 181, no. 3, pp. 257-266, 1997.

[58] R. E. Kast, "Tumor necrosis factor has positive and negative self regulatory feed back cycles centered around cAMP," International Journal of Immunopharmacology, vol. 22, no. 11, pp. 10011006, 2000.

[59] U. Andersson and K. J. Tracey, “HMGB1 in sepsis," Scandinavian Journal of Infectious Diseases, vol. 35, no. 9, pp. 577-584, 2003.

[60] J. A. Nogueira-Machado and V. C. de Oliveira, "HMGB-1 as a target for inflammation controlling," Recent Patents on Endocrine, Metabolic \& Immune Drug Discovery, vol. 6, no. 3, pp. 201-209, 2012.

[61] H. Yang and K. J. Tracey, "Targeting HMGB1 in inflammation," Biochimica et Biophysica Acta, vol. 1799, no. 1-2, pp. 149-156, 2010.

[62] J. S. Bae, "Role of high mobility group box 1 in inflammatory disease: focus on sepsis," Archives of Pharmacal Research, vol. 35, no. 9, pp. 1511-1523, 2012.

[63] W. Huang, Y. Tang, and L. Li, "HMGB1, a potent proinflammatory cytokine in sepsis," Cytokine, vol. 51, no. 2, pp. 119-126, 2010.

[64] S. Karlsson, V. Pettilä, J. Tenhunen, R. Laru-Sompa, M. Hynninen, and E. Ruokonen, "HMGB1 as a predictor of organ dysfunction and outcome in patients with severe sepsis," Intensive Care Medicine, vol. 34, no. 6, pp. 1046-1053, 2008.

[65] A. Fung, M. Vizcaychipi, D. Lloyd, Y. Wan, and D. Ma, “Central nervous system inflammation in disease related conditions: mechanistic prospects," Brain Research, vol. 1446, pp. 144-155, 2012.

[66] J. I. Granger, P. L. Ratti, S. C. Datta et al., "Sepsis-induced morbidity in mice: effects on body temperature, body weight, cage activity, social behavior and cytokines in brain," Psychoneuroendocrinology, vol. 38, no. 7, pp. 1047-1057, 2013.

[67] C. M. Comim, M. C. Vilela, L. S. Constantino et al., "Traffic of leukocytes and cytokine up-regulation in the central nervous system in sepsis," Intensive Care Medicine, vol. 37, no. 4, pp. 711718, 2011.

[68] M. D. Laird, J. S. Shields, S. Sukumari-Ramesh et al., "High mobility group box protein-1 promotes cerebral edema after traumatic brain injury via activation of toll-like receptor 4," Glia, vol. 62, no. 1, pp. 26-38, 2014.

[69] A.-F. Petit-Bertron, C. Fitting, J.-M. Cavaillon, and M. AdibConquy, "Adherence influences monocyte responsiveness to interleukin-10," Journal of Leukocyte Biology, vol. 73, no. 1, pp. 145-154, 2003.
[70] H. Sies and E. Cadenas, "Oxidative stress: damage to intact cells and organs," Philosophical Transactions of the Royal Society of London B: Biological sciences, vol. 311, no. 1152, pp. 617-631, 1985.

[71] S.-S. Sheu, D. Nauduri, and M. W. Anders, "Targeting antioxidants to mitochondria: a new therapeutic direction," Biochimica et Biophysica Acta, vol. 1762, no. 2, pp. 256-265, 2006.

[72] J. F. Turrens, "Mitochondrial formation of reactive oxygen species," The Journal of Physiology, vol. 552, no. 2, pp. 335-344, 2003.

[73] A. C. Carr, M. R. McCall, and B. Frei, "Oxidation of LDL by myeloperoxidase and reactive nitrogen species: reaction pathways and antioxidant protection," Arteriosclerosis, Thrombosis, and Vascular Biology, vol. 20, no. 7, pp. 1716-1723, 2000.

[74] C. Szabó, H. Ischiropoulos, and R. Radi, "Peroxynitrite: biochemistry, pathophysiology and development of therapeutics," Nature Reviews Drug Discovery, vol. 6, no. 8, pp. 662-680, 2007.

[75] W.-J. Liaw, T.-H. Chen, Z.-Z. Lai et al., "Effects of a membranepermeable radical scavenger, tempol, on intraperitoneal sepsisinduced organ injury in rats," Shock, vol. 23, no. 1, pp. 88-96, 2005.

[76] S. Ohta, "Hydrogen gas and hydrogen water act as a therapeutic and preventive antioxidant with a novel concept," Nihon Ronen Igakkai Zasshi, vol. 45, no. 4, pp. 355-362, 2008.

[77] J. Cai, Z. Kang, W. W. Liu et al., "Hydrogen therapy reduces apoptosis in neonatal hypoxia-ischemia rat model," Neuroscience Letters, vol. 441, no. 2, pp. 167-172, 2008.

[78] Y.-F. Mao, X.-F. Zheng, J.-M. Cai et al., "Hydrogen-rich saline reduces lung injury induced by intestinal ischemia/reperfusion in rats," Biochemical and Biophysical Research Communications, vol. 381, no. 4, pp. 602-605, 2009.

[79] S. Biswal and D. G. Remick, "Sepsis: redox mechanisms and therapeutic opportunities," Antioxidants \& Redox Signaling, vol. 9, no. 11, pp. 1959-1961, 2007.

[80] A. Nunomura, P. I. Moreira, H. G. Lee et al., "Neuronal death and survival under oxidative stress in Alzheimer and Parkinson diseases," CNS \& Neurological Disorders-Drug Targets, vol. 6, no. 6, pp. 411-423, 2007.

[81] W. Hoetzenecker, B. Echtenacher, E. Guenova et al., "ROSinduced ATF3 causes susceptibility to secondary infections during sepsis-associated immunosuppression," Nature Medicine, vol. 18, no. 1, pp. 128-134, 2012.

[82] M. O. Hengartner, "The biochemistry of apoptosis," Nature, vol. 407, no. 6805, pp. 770-776, 2000.

[83] J. Chandra, A. Samali, and S. Orrenius, "Triggering and modulation of apoptosis by oxidative stress," Free Radical Biology and Medicine, vol. 29, no. 3-4, pp. 323-333, 2000.

[84] L. Xiang, J. W. Tan, L. J. Huang et al., "Inhalation of hydrogen gas reduces liver injury during major hepatotectomy in swine," World Journal of Gastroenterology, vol. 18, no. 37, pp. 5197-5204, 2012.

[85] A. Yoshida, H. Asanuma, H. Sasaki et al., " $\mathrm{H}_{2}$ mediates cardioprotection via involvements of $\mathrm{K}_{\mathrm{ATP}}$ channels and permeability transition pores of mitochondria in dogs," Cardiovascular Drugs and Therapy, vol. 26, no. 3, pp. 217-226, 2012.

[86] W. Wang, L. Tian, Y. Li et al., "Effects of hydrogen-rich saline on rats with acute carbon monoxide poisoning," The Journal of Emergency Medicine, vol. 44, no. 1, pp. 107-115, 2013.

[87] B. Hoesel and J. A. Schmid, “The complexity of NF- $\kappa$ B signaling in inflammation and cancer," Molecular Cancer, vol. 12, article 86, 2013. 
[88] M. J. Morgan and Z.-G. Liu, "Crosstalk of reactive oxygen species and NF- $\kappa \mathrm{B}$ signaling," Cell Research, vol. 21, no. 1, pp. 103-115, 2011.

[89] Z. Zhuang, X. J. Sun, X. Zhang et al., "Nuclear factor- $\kappa \mathrm{B} / \mathrm{Bcl}$ $\mathrm{XL}$ pathway is involved in the protective effect of hydrogenrich saline on the brain following experimental subarachnoid hemorrhage in rabbits," Journal of Neuroscience Research, vol. 91, no. 12, pp. 1599-1608, 2013.

[90] C.-S. Huang, T. Kawamura, X. Peng et al., "Hydrogen inhalation reduced epithelial apoptosis in ventilator-induced lung injury via a mechanism involving nuclear factor- $\kappa \mathrm{B}$ activation," Biochemical and Biophysical Research Communications, vol. 408, no. 2, pp. 253-258, 2011.

[91] G. Song, H. Tian, J. Liu, H. Zhang, X. Sun, and S. Qin, " $\mathrm{H}_{2}$ inhibits TNF- $\alpha$-induced lectin-like oxidized LDL receptor1 expression by inhibiting nuclear factor $\kappa \mathrm{B}$ activation in endothelial cells," Biotechnology Letters, vol. 33, no. 9, pp. 17151722, 2011.

[92] M. Kobayashi and M. Yamamoto, "Molecular mechanisms activating the Nrf2-Keap1 pathway of antioxidant gene regulation," Antioxidants \& Redox Signaling, vol. 7, no. 3-4, pp. 385-394, 2005.

[93] T. Satoh, S.-I. Okamoto, J. Cui et al., "Activation of the Keap1/Nrf2 pathway for neuroprotection by electrophillic phase II inducers," Proceedings of the National Academy of Sciences of the United States of America, vol. 103, no. 3, pp. 768-773, 2006.

[94] R. K. Thimmulappa, H. Lee, T. Rangasamy et al., "Nrf2 is a critical regulator of the innate immune response and survival during experimental sepsis," The Journal of Clinical Investigation, vol. 116, no. 4, pp. 984-995, 2006.

[95] S. W. Chung, X. Liu, A. A. Macias, R. M. Baron, and M. A. Perrella, "Heme oxygenase-1-derived carbon monoxide enhances the host defense response to microbial sepsis in mice," The Journal of Clinical Investigation, vol. 118, no. 1, pp. 239-247, 2008.

[96] T. Kawamura, N. Wakabayashi, N. Shigemura et al., "Hydrogen gas reduces hyperoxic lung injury via the Nrf2 pathway in vivo," American Journal of Physiology: Lung Cellular and Molecular Physiology, vol. 304, no. 10, pp. L646-L656, 2013.

[97] A. Y. Shih, D. A. Johnson, G. Wong et al., "Coordinate regulation of glutathione biosynthesis and release by Nrf2-expressing glia potently protects neurons from oxidative stress," The Journal of Neuroscience, vol. 23, no. 8, pp. 3394-3406, 2003.

[98] X. Zheng, Y. Mao, J. Cai et al., "Hydrogen-rich saline protects against intestinal ischemia/reperfusion injury in rats," Free Radical Research, vol. 43, no. 5, pp. 478-484, 2009.

[99] C. Chen, Q. Chen, Y. Mao et al., "Hydrogen-rich saline protects against spinal cord injury in rats," Neurochemical Research, vol. 35, no. 7, pp. 1111-1118, 2010.

[100] C. Wang, J. Li, Q. Liu et al., "Hydrogen-rich saline reduces oxidative stress and inflammation by inhibit of JNK and NF- $\kappa \mathrm{B}$ activation in a rat model of amyloid-beta-induced Alzheimer's disease," Neuroscience Letters, vol. 491, no. 2, pp. 127-132, 2011.

[101] J. Zhou, Y. Chen, G.-Q. Huang et al., "Hydrogen-rich saline reverses oxidative stress, cognitive impairment, and mortality in rats submitted to sepsis by cecal ligation and puncture," Journal of Surgical Research, vol. 178, no. 1, pp. 390-400, 2012.

[102] A. M. James, H. M. Cochemé, and M. P. Murphy, "Mitochondria-targeted redox probes as tools in the study of oxidative damage and ageing," Mechanisms of Ageing and Development, vol. 126, no. 9, pp. 982-986, 2005. 


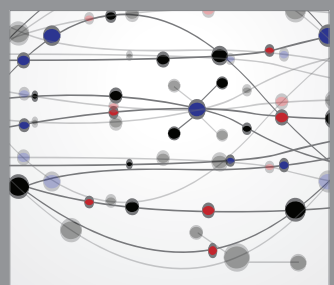

The Scientific World Journal
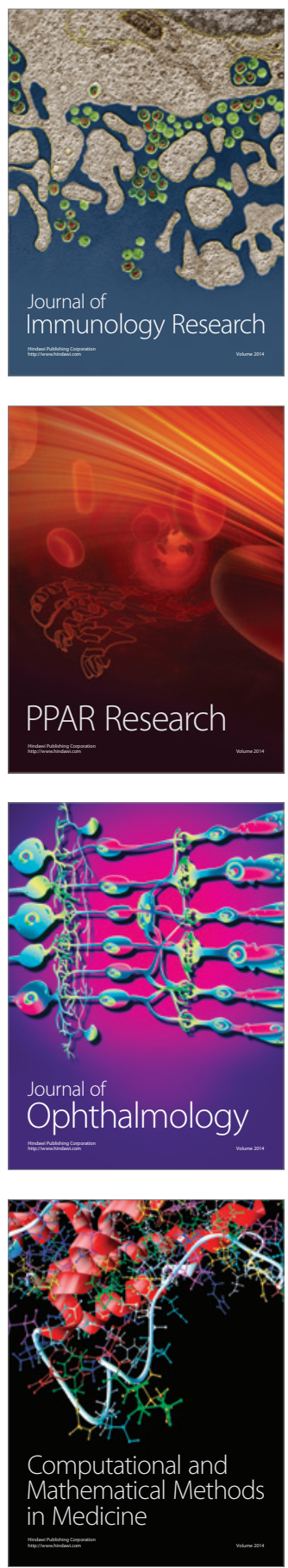

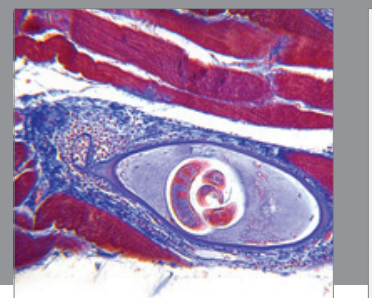

Gastroenterology

Research and Practice
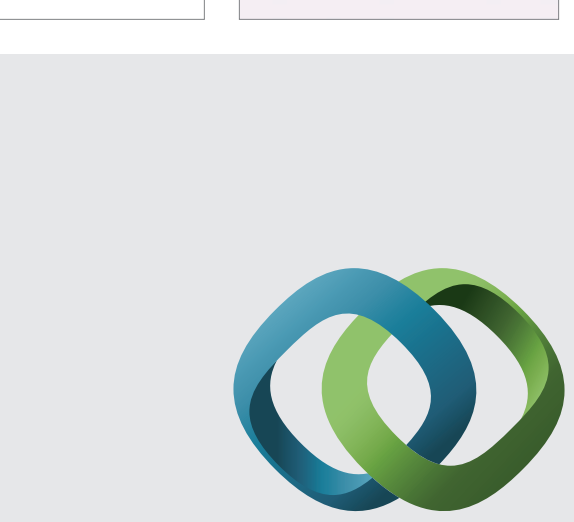

\section{Hindawi}

Submit your manuscripts at

http://www.hindawi.com
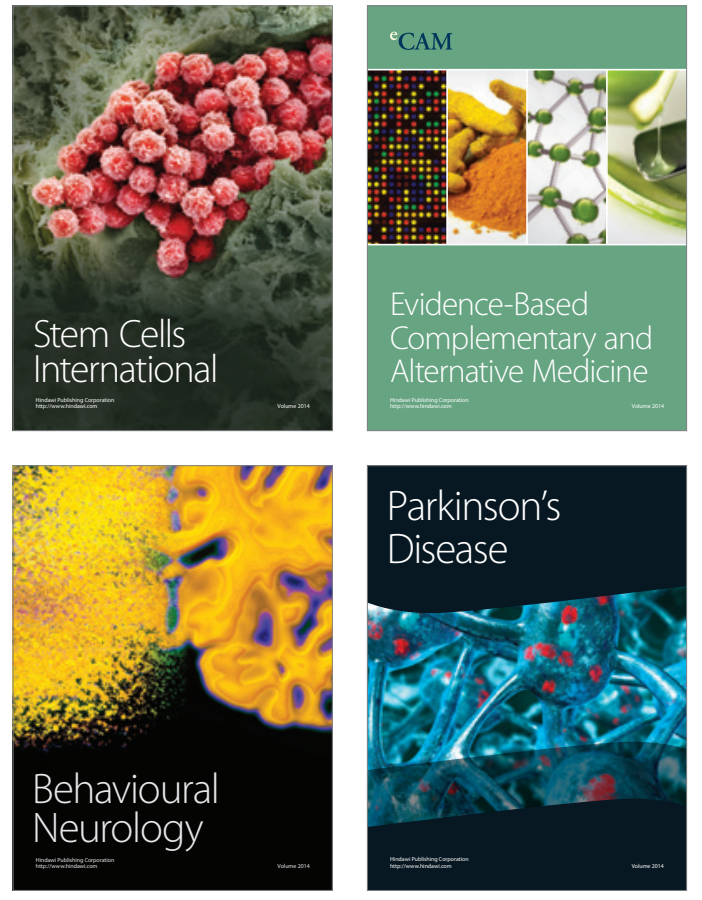
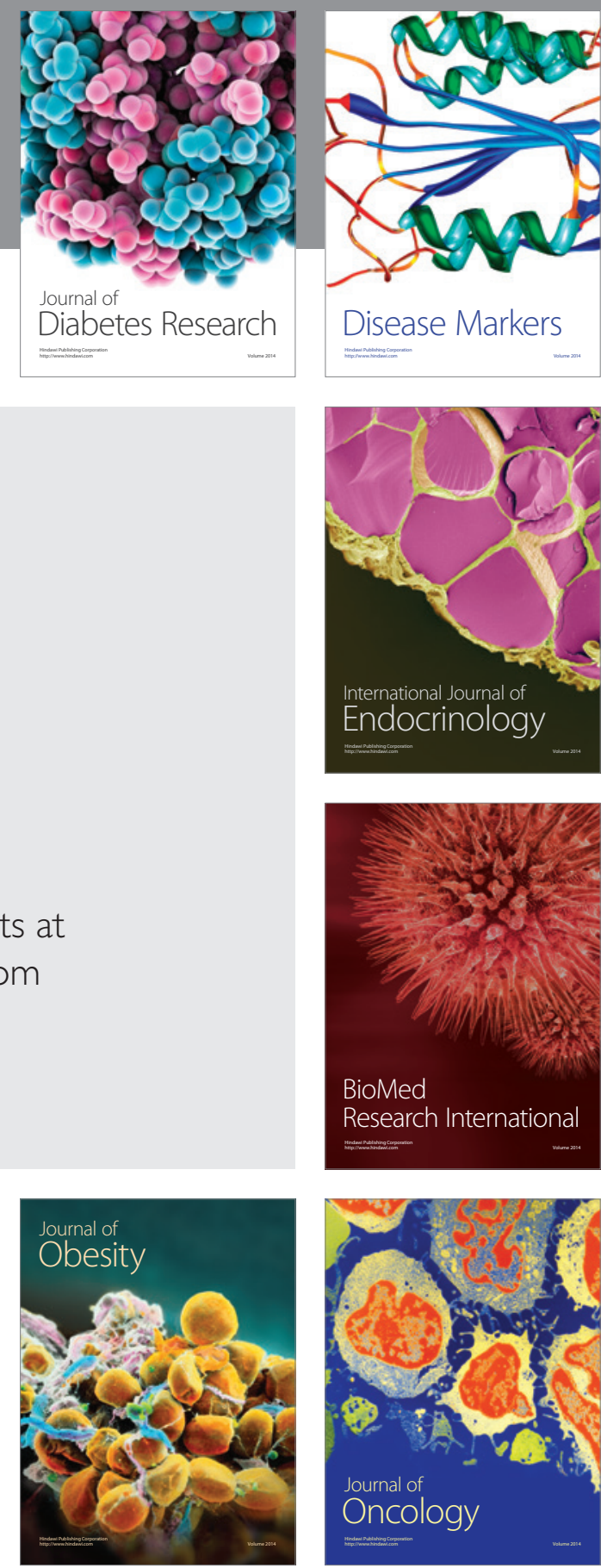

Disease Markers
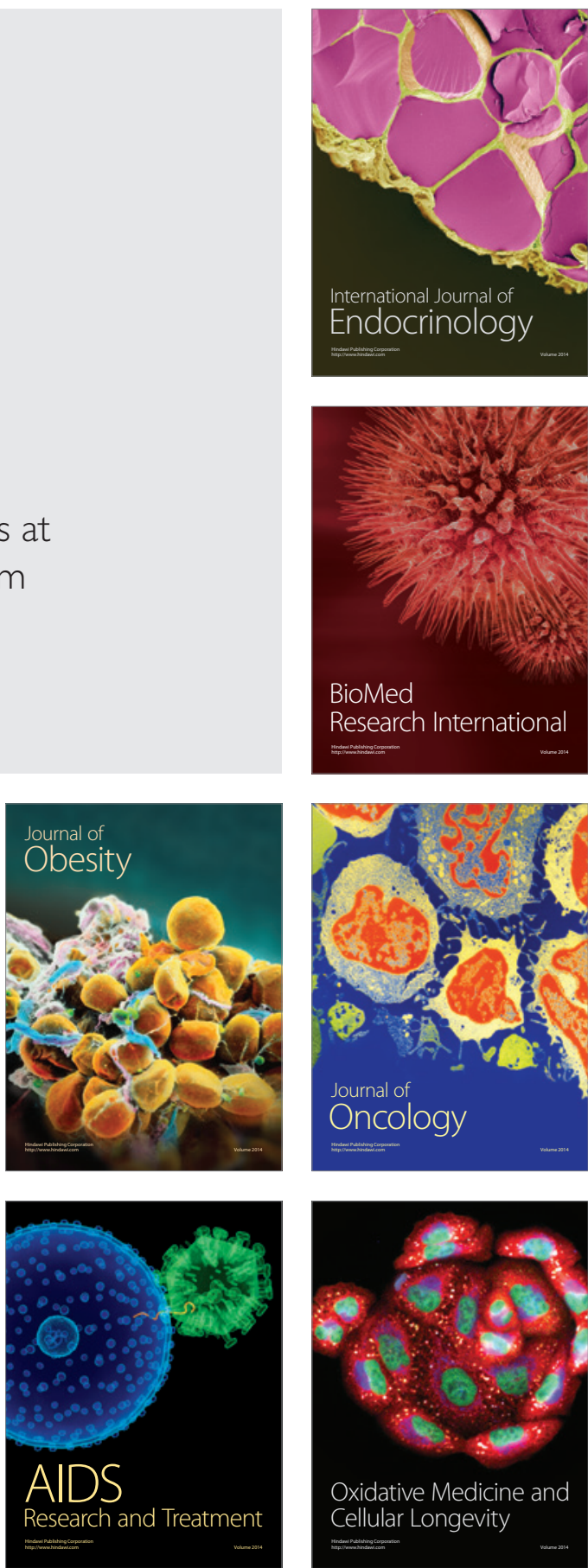